\title{
Temporomandibular dysfunction and functional mandibular limitation
}

\author{
Élcio Alves Guimarães', Kelly Duarte Lima Makhoul', Cristina de Matos Boaventura', Ana Luiza Ferreira', \\ Lucas Resende Sousa², Renato Mota da Silva ${ }^{3}$, Kennedy Rodrigues Lima ${ }^{3}$
}

\begin{abstract}
Background: The temporomandibular dysfunction (TMD) is one of the most complex disorders of the body, capable of triggering changes in mandibular function and speech articulation. In the case of teachers, probably due to long periods of speech, since it is known that most of them work in classrooms with too many students, end up making use of the voice incorrectly and may lead to changes in the function of the stomatognathic system. Objective: To investigate the association between TMD and mandibular functional limitation in teachers of an elementary school in the city of Uberlandia. Methods: The study was carried out in 49 teachers. The data were collected through Helkimo's Clinical Dysfunction Index (IDCCM) and Mandibular Function Impairment Questionnaire (MFIQ). Results: It was observed that all teachers in both genders showed some degree of TMD and, consequently, the higher the TMD degree the greater is the changing the jaw function. Conclusions: Based on the data and through studies carried out with this group of teachers, it is concluded that as the TMD degree increases, it causes alteration of the mandibular function and can lead to a decreased in the mandibular amplitude and to limit movement.
\end{abstract}

Keywords: Temporomandibular Dysfunction, Mandibular Functional Limitation, Teachers.

\section{INTRODUCTION}

The stomatognathic system (SS) is a set of structures formed by the temporomandibular joint (TMJ), ligaments, nerves, vessels, muscles and teeth ${ }^{(1)}$. The TMJ is one of the elements of the SS, and this, is a functional unit organ formed by several internal and external structures that act in harmony to perform several functional tasks, such as chewing, phonation, swallowing and breathing ${ }^{(2)}$. These structures are interconnected and form a system with their own characteristics, located in the oral cavity, and are not specialized in a single function. Therefore, changes in any of its parts lead to a global imbalance of the system. TMJ is able to perform complex movements associated with the action of chewing muscles, allowing the performance of neurovegetative functions, including speech ${ }^{(3,4)}$. Temporomandibular dysfunction (TMD) is a widely used term that involves several clinical problems and a wide range of changes in the masticatory muscles, TMJ and associated bone structures, which has so many problems with complex symptoms and rarely presented separately. Likewise, temporomandibular disorders include not only any disharmony of the joints and muscles of the SS, but also the presence of neck pain, limitation of mandibular movements and joint noises ${ }^{(5,6)}$.
TMD directly interfere in the muscles of the jaw and neck as a result of inadequate posture of movement of the head and hyoid bone. As a result, the supra-hyoid muscles and laryngeal activity can be altered. Speech due to this disharmony is compromised. Prolonged use of the voice is a prerequisite for the appearance of severe laryngeal tension, pain symptoms in TMJ and difficulty in performing mandibular movements ${ }^{(7)}$. The execution of speech involves mobile and fixed organizers of the SS, which are controlled by the central nervous system. To express verbally, it is necessary integrity and harmony between orofacial structures for the production of sounds, in addition to a linguistic need. However, if there is a bone and/or muscle alteration, the disorder in the joint may appear ${ }^{(8)}$.

Epidemiological studies suggest that the prevalence of symptoms such as pain and circulation restriction varies between 5 and 15\%, with most cases occurring in young adults between the ages of 20 and 40 , especially in the female gender ${ }^{(9)}$. Temporomandibular dysfunction and orofacial pain are problems that affect the majority of the population and have clinical signs that limit movements of the mandible, which may interfere with acoustics. However, there are few reports about the frequency and degree of impairment of these

Corresponding author: Élcio Alves Guimarães. Address: Av Dos Vinhedos, 900 Bairro Morada da Colina, Uberlândia - MG, Brazil. CEP $38411-159$.

Phone: +55 34 99687-4951. E-mail: elcio@unitri.edu.br

${ }^{1}$ Centro Universitário do Triângulo (UNITRI), Uberlândia - MG, Brazil.

Full list of author information is available at the end of the article.

Financial support: The authors declare that there was no financial support.

Submission date 08 January 2018; Acceptance date 05 March 2018; Publication date 27 March 2018 
movements and the TMJ involved in the muscular alterations related to the voice ${ }^{(6)}$. The voice has a very important role since it is considered essential for communication and relationships. Thus the voice is part of the daily life of society in different roles played by people in social life as a result of a combination of biological, psychological and social factors ${ }^{(10)}$. The range and precision of mandibular movements depend on the health and integrity of orofacial structures. There may be impairments in speech articulation and voice quality, associated with TMJ disorders, such as reduction of mandibular motion amplitude, vocal quality changes and laterality deviations during speech ${ }^{(11)}$.

The amplitude and precision of the mandibular movements is related to the integrity of the TMJ and the action of the skeletal muscles. However, unfavorable conditions are frequent because the joint supports and accommodates several other structures. If the functional demands exceed the structural and functional tolerance of TMJ, it result in changes in mandibular movements and associated stomatognathic functions. The presence of pain also leads to reduced range of motion $^{(1)}$. Restriction or limitation of mandibular movements may alter the functional balance of the mandible and may be attributed to mechanical impairment or functional adaptation to avoid pain, discomfort, and muscle fatigue. The coordination of movements used in speech involves substantial adjustments related to the control of various muscles and the possibility of the movements involved, providing minimal, fast and fundamental changes to the variability of articulation production ${ }^{(4)}$. Regarding neuromotor control of speech, it is also reported that cortical and subcortical brain regions are involved, in order to prepare and execute movements that can be altered due to peripheral structural alterations. The nature of the rapid movements used in speech suggests the need for significant mechanisms of motor adjustments at minimal intervals, directly dependent on neural control. It is possible that the limitation of mandibular movement leads to a greater laryngeal effort, as compensation, leading to a change in vocal quality, justifying the appearance of hoarseness as a complaint of subjects ${ }^{(4)}$.

The teachers are in a professional category in which the voice is considered one of the main instruments of work and, therefore, they are predisposed to develop vocal and SS changes ${ }^{(12)}$. The symptoms of pain when talking too much, pain at the end of the day and popping on TMJ when opening and closing the mouth seem to be related excessive activity of the orofacial muscles, imbalance in TMJ and disharmony in the laryngeal structure due to prolonged use of the voice. In the case of teachers, this is probably due to long periods of speech, since most of them are known to operate in classrooms with excessive numbers of students, under adverse noise conditions, and therefore end up using the voice incorrectly ${ }^{(7)}$.

Helkimo was one of the pioneers to develop an index to assess TMD. The initial studies that led to it sought an epidemiological investigation of the function and dysfunction of the masticatory system in Finland. The Helkimo's Clinical Dysfunction Index (IDCCM), classifies the volunteers into severity categories of the clinical signs of $\mathrm{TMD}^{(13)}$. The Mandibular Function Impairment Questionnaire (MFIQ) has a punctuation system that characterizes it as an index, making it possible to classify volunteers into severity categories of TMD-related functional limitation. Its great advantage is that it measures functional limitation of TMD, unlike other indexes that specifically assess the severity of clinical signs and symptoms ${ }^{(14)}$. The relevance of this research was in the analysis of temporomandibular dysfunction and functional mandibular limitation in teachers of an elementary school in the city of Uberlândia, in order to improve academic knowledge and raise specific data about the subjects, since there are few studies related to the theme. The research in question had as objective to verify the association and to classify in degrees of gravity the TMD and mandibular functional limitation in teachers.

\section{METHODS}

This was an exploratory and descriptive study with a quantitative approach, in which data were collected from 49 teachers of a public elementary school, after the authorization of the responsible of the institution in the city of Uberlândia. Primary school teachers, with and without pain complaints, of both genders and without age discrimination, who agreed to participate in the study, were included in the study. Professionals from the field of education who did not act in class regency and who did not sign the Free and Informed Consent Term were excluded from the survey. The data collection was performed with the use of the Helkimo's Clinical Dysfunction Index (IDCCM) and the Mandibular Function Impairment Questionnaire (MFIQ). To evaluate the degree of TMD of the participants, the Helkimo Index was used, which was subdivided into five items. Initially, limitation of mandibular range of motion was measured through the stainless steel pachymeter sterilized with $70 \%$ alcohol according to norms established by "Agência Nacional de Vigilância Sanitária" (ANVISA, Brazil), measuring the buccal opening between the central, upper and lower incisors, and the assessed teacher was in the position of Frankfurt, i.e. the natural position of the head aligned with the cervical spine, determined by the balance of the head and body when the subject looks forward in sitting position. Also in this same position, the limitation of the TMJ function was evaluated through the auscultation with the Littmann stethoscope, and was performed the palpation of the joint, observing whether the presence of pain in TMJ function or the mandibular movement existed. Afterwards the teacher was invited to lie down on a portable stretcher provided by the examiner, accommodated in a reserved room, in which the sensitivity of the extra and intraoral muscles was evaluated through the palpation technique, and at the time of palpation of intraoral muscles, was used latex gloves. For the analysis of the questionnaire, the answers were added 
and the value attributed to each of them was found the TMJ dysfunction index, which was classified from 0 to 5 , and its classification being with no, mild, moderate, and severe dysfunction. After that the professors were invited to answer the Mandibular Function Impairment Questionnaire (MFIQ), composed of 17 questions, with independent variables as gender and age and dependent variables as complaints about difficulty in performing speech, eating, working and / or performing their daily activities of life, laughing, yawning and kissing. The questionnaire has five possible answers with values from 0 to 4 and the total punctuation is obtained adding the values of the answers to each question, and this questionnaire was completed by the teachers using blue or black pens. All teachers participating in the study were evaluated by a single researcher who rigorously followed the chosen methodology.

The data obtained in the research were organized, tabulated and analyzed in the Microsoft Excel 2007 and the results were presented in the form of graphs and tables, being the same ones confronted with the existing literature in national and international level. This research followed the norms of the National Health Council, in accordance with the resolution 050229/2015, and was submitted to the appreciation of the Ethics and Research Committee of the Centro Universitário do Triângulo with number 1.257.262.

\section{RESULTS}

Participated in this study, 49 teachers with 11 males (22.45\%) and 38 females (77.55\%), presenting the average age of 43 years and two months. The teachers answered the Mandibular Functional Limitation Questionnaire (MFIQ) and the Helkimo Index Questionnaire for TMD classification. All teachers had some degree of TMD and no teacher was classified as severely for Mandibular Functional Limitation Index.

Also called cross-table with percentages in the column, the Table 1 is used to perform analyzes that favor the comparison between the respondents of the same column ${ }^{(15)}$. In the example, the analysis should be done by degree of TMD (mild, moderate or severe). The description is made above the classification of the degree of limitation of the teachers, as none, low or moderate.

Based on the results presented in Table 1, it can observe that $39 \%$ of the teachers presented no limitations, $43 \%$ with low and $18 \%$ with moderate. Regarding teachers who presented mild TMD, the majority (64\%) of them presented no limitation, i.e., the lowest degree of TMD, with consequent lower limitation. And the majority (55\%) of teachers who had moderate TMD had no limitations and $40 \%$ presented low limitation. When observing the teachers who presented severe TMD, the majority (50\%) of them presented low limitation and $44 \%$ presented moderate limitation. In this case, we can observe that the highest degree of TMD corresponds to "higher" classifications of limitation.

It can be observed in the figure 1 that when the degree of TMD increases, the limitation also increases and the lower the degree of TMD, the lower the limitation of the teacher. This information can be perceived when analyzing, for example, that when the degree of TMD is determined as mild, any teacher presented moderate limitation and most of them did not present limitation at all. The same happens when we analyze the degree of moderate TMD, i.e., only one teacher presented moderate limitation.

Table 2 shows the frequencies of teachers, which were classified with some degree of TMD impairment and limitation. In parentheses, the expected frequencies used to verify the

Table 1 - Cross table for the total criteria in column.

\begin{tabular}{ccccc}
\hline \multicolumn{5}{c}{ Temporomandibular Dysfunction } \\
\hline Limitation & MI & M & S & Total \\
\hline N & $64 \%$ & $55 \%$ & $6 \%$ & $39 \%$ \\
L & $36 \%$ & $40 \%$ & $50 \%$ & $43 \%$ \\
M & $0 \%$ & $5 \%$ & $44 \%$ & $18 \%$ \\
Total & $100 \%$ & $100 \%$ & $100 \%$ & $100 \%$ \\
\hline
\end{tabular}

Note: $\mathrm{N}=$ none; $\mathrm{L}=$ low; $\mathrm{M}=$ moderate; $\mathrm{MI}=$ mild; $\mathrm{S}=$ severe.

Table 2 - Frequencies distribution, according to the classification obtained in Temporomandibular Dysfunction and limitation.

\begin{tabular}{cccccc}
\hline \multicolumn{7}{c}{ TMD } \\
\hline Limitation & N & MI & M & S & Total \\
\hline N & $0(0)$ & $7(4)$ & $11(8)$ & $1(7)$ & $\mathbf{1 9}$ \\
L & $0(0)$ & $4(5)$ & $8(9)$ & $9(8)$ & $\mathbf{2 1}$ \\
M & $0(0)$ & $0(2)$ & $1(4)$ & $8(3)$ & $\mathbf{9}$ \\
S & $0(0)$ & $0(0)$ & $0(0)$ & $0(0)$ & $\mathbf{0}$ \\
Total & $\mathbf{0}$ & $\mathbf{1 1}$ & $\mathbf{2 0}$ & $\mathbf{1 8}$ & $\mathbf{4 9}$ \\
\hline
\end{tabular}

Note: $T M D=$ Temporomandibular Dysfunction ; $N=$ none; $L=$ low; $M=$ moderate; $\mathrm{S}=$ severe; $\mathrm{MI}=$ mild.

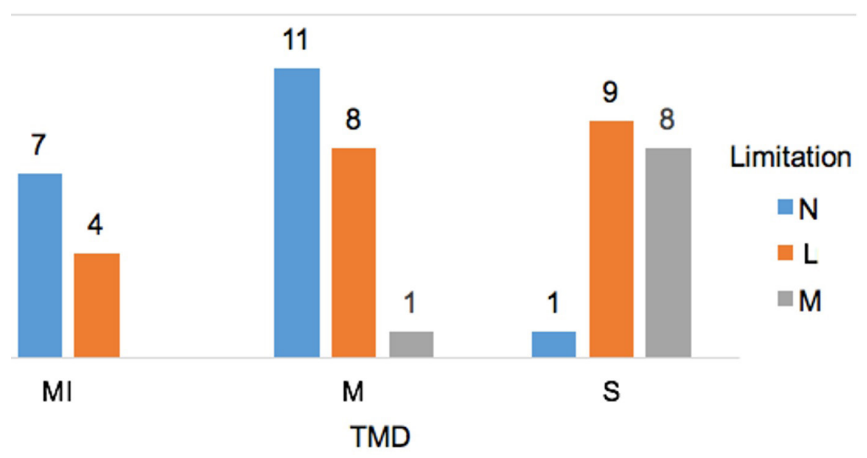

Figure 1 - Distribution of the frequency observed regarding the degree of Temporomandibular Dysfunction due the mandibular functional limitation. Note: $\mathrm{TMD}=$ Temporomandibular Dysfunction; $\mathrm{N}=$ none; $\mathrm{L}=$ low; $\mathrm{M}=$ moderate; $\mathrm{Ml}=$ mild; $\mathrm{S}=$ severe. 
relationship between the variables. When the total results were analyzed, for the group of teachers who presented mild TMD degree, the majority (7 teachers) presented no limitation. It was observed that the moderate TMD degree was more frequent and when analyzing only this group, the majority (11 teachers) presented the degree of limitation classified as none. Regarding the degree of TMD classified as severe, it was observed that the limitations described as low (9 teachers) and moderate (8 teachers) presented higher frequency. In order to verify the existence or non-existence of a statistically significant correlation between the classification of teachers in the mandibular functional limitation and regarding TMD, the chi-square test was applied. This non-parametric test was used because it was two qualitative and independent variables, as determined for the use of the test described in the study ${ }^{(16)}$. The calculated chi-square is obtained through $\chi_{\text {calc. }}^{2}=\Sigma\left(\frac{(\mathrm{o}-\mathrm{e})^{2}}{\mathrm{e}}\right)$, with "o" being the observed frequency and " $e$ " the expected frequency for each classification. The value obtained through the expression was given by $\chi_{\text {calc. }}^{2}=19.22$, indicating that there is a significant association $\left(\chi_{\text {calc. }}^{2}>\chi_{\text {tab. }}^{2}\right)$ between the variables TMD and limitation, because $\chi_{\text {tab. }}^{2}=9.488$. The level of significance was set at 0.05 in a bilateral test and 4 degrees of liberty. This indicates that, as the values of one of the variables increases, the values of the other variables also increase and consequently as the values of one of the variables decreases, the values of the other variables also decrease.

\section{DISCUSSION}

This study verified the association of TMD and mandibular functional limitation in teachers of an elementar school in Uberlândia, using the validated Helkimo Index and Mandibular Functional Limitation Questionnaire (MFIQ). The diagnosis of the presence of signs and symptoms of TMD and associated factors, whether predisposing or disturbing, can be performed through instruments that use questionnaires and/or physical exams $^{(17)}$. Recent studies evaluating TMD in teachers showed a higher prevalence in females. But in this study the same assertion cannot be made, since the sample composed of 49 teachers presents a higher proportion of females than males, however, all the teachers who participated in our research presented some degree of TMD ${ }^{(7,18)}$. In some studies, the simplified anamnestic questionnaire, Fonseca's Anamnestic Index was used, which was elaborated according to the Helkimo anamnestic Index. Due to the simplicity of this index, it favors its use in population epidemiological studies. However, it has not yet been completely validated and also does not offer a diagnostic classification of TMD ${ }^{(5,13,19)}$. Although there are few studies that identify the degree of TMD in elementary school teachers, some authors describe a positive relationship between TMD and voice changes in higher education professors, due to the aspect that teachers are constantly undergoing. The teacher is included in a category in which the voice is considered one of the main instruments of work, that leads to a predisposition to develop vocal and TMD alterations ${ }^{(12,18,20)}$.

It was verified that the lower the mouth opening, or the lowering of the mandible, the weaker the intensity of the voice. The results presented in this study showed that subjects with severe symptomatology showed a tendency to present a lower mouth opening during phonation due to the presence of pain in the masticatory muscles, preventing subjects from opening their mouths well, leading to an increase of voice resonance ${ }^{(6)}$. Patients with TMD showed more restricted movements in mandibular activity, when compared with asymptomatic subjects $^{(21)}$. In a study conducted in patients with severe dysfunction, there is an impact of pain in their lives, referring to the relationship of pain and reduction of mandibular amplitude with the degree of TMD. A statement that corroborates with our results, because the higher the degree of TMD presented by the teachers in our research, the higher was the degree of mandibular functional limitation, proving that TMD and limitation may be associated ${ }^{(6)}$. Another established relationship, which may justify the probable relationship between the degree of dysfunction symptomatology and vocal production, is related to the presence of TMD and body alteration. The TMJ is directly related to the cervical and scapular region. Observing that individuals with symptoms of TMD present exaggerated muscular tension, and such behavior may influence cervical muscle tension, and consequently, will cause alterations in the voice of these individuals ${ }^{(6)}$. In a study that evaluated TMD in elementary school teachers, $50.8 \%$ of them had TMD; however, only $3.5 \%$ of the teachers participating in the study had a MFIQ with a moderate degree of functional impairment. In this study, there was no verification of the association between the degrees of TMD and functional mandibular limitation ${ }^{(5)}$. Regarding the MIFQ, it can be said that this instrument is gaining more recognition in the scientific environment, since it is considered one of the most appropriate instruments to be used. In a very interesting study, the authors proposed that the greater advantage of MIFQ is the measure of functional limitation related to TMD, unlike other indices that specifically assess the severity of clinical signs and symptoms ${ }^{(14)}$. Although a comparison of the validity of MFIQ in the study ${ }^{(22)}$ of Campos et al. (2012) is hard, because only the study ${ }^{(23)}$ of Ohrbach et al. (2008) provided information on the validity of this instrument.

\section{CONCLUSION}

Based on the data and through studies carried out with this group of teachers, it is concluded that as the TMD degree increases, it causes alteration of the mandibular function and can lead to a decreased in the mandibular amplitude and to limit movement. 


\section{AUTHOR'S CONTRIBUTION}

EAG: study design and guided the entire execution of the study; KDLM: guided the entire execution of the study and critical review; CMB: Data collection and statistical analysis; ALF: Data collection and tabulation of collected data; LRS: statistical analysis; RMS: Data collection, elaboration of the discussion and critical review; KRL: Data collection, statistical analysis, elaboration of the conclusion and review of the article. All authors read and approved the final manuscript.

\section{CONFLICTS OF INTEREST}

The authors declare that there was no conflict of interests.

\section{AUTHOR DETAILS}

2 Universidade Federal de Uberlândia (UFU), Uberlândia - MG, Brazil. ${ }^{3}$ Physiotherapy Master Degree Post-graduation program, Universidade Federal de Uberlândia / Universidade Federal do Triângulo Mineiro (UFU/UFTM), Uberlândia / Uberaba - MG, Brazil.

\section{REFERENCES}

1- Cronemberger AMD, Silva MA, Bonfim RVF. Efeito da manipulação miofascial na limitação da abertura funcional da boca. Rev. Ter. Man. 2011;9(46):800-4.

2- Saes MO, Nogueira DB, Da Silveira MS, Siqueira FCV. Perfil epidemiológico dos pacientes com disfunção temporomandibular: uma abordagem fisioterápica. Revista Inspirar movimento e saúde. 2013;5(1):1-5.

3- Machado PG, Mezzomo CL, Badaró AFV. A postura corporal e as funções estomatognáticas em crianças respiradoras orais: uma revisão de literatura. Rev. CEFAC. 2012;14(3):553-65.

4- Taucci RA, Bianchini EMG. Verificação da interferência das disfunções temporomandibulares na articulação da fala: queixas e caracterização dos movimentos mandibulares. Rev. Soc. Bras. Fonoaudiologia. 2007;12(4):274-80.

5- Silva CV, De Faria CA, De Oliveira RG, Paiva Oliveira EL. Disfunções temporomandibulares: prevalência e gravidade em professores. Revista Científica da Faminas. 2015;11(1):39-46.

6- Silva AMT, Morisso MF, Cielo CA. Relação entre grau de severidade de disfunção temporomandibular e a voz. Pró-Fono Revista de Atualização Científica. 2007;19(3):279-88.

7- Machado IM, Bianchini EMG, Boas DCV, Giannini SPP, Ferreira LP. Associação entre distúrbio de voz e sintomas de disfunção temporomandibular autorreferidos por professores. Audiol., Commun. Res. 2014;19(1):75-80.

8- Berwig LC, Da Silva AMT, Busanello AR, De Almeida FL, Bolzan GP, Hennig $T R$, et al. Alterações no modo respiratório, na oclusão e na fala em escolares: ocorrências e relações. Rev CEFAC. 2010;12(5):795-802.

9- Maydana AV, Tesch RDS, Denardin OVP, Ursi WJDS, Dworkin SF. Possíveis fatores etiológicos para desordens temporomandibulares de origem articular com implicações para diagnóstico e tratamento. Dental Press J Orthod. 2010;15(3):78-86.
10- Zimmer V, Cielo CA, Finger LS. Modificações vocais acústicas espectrográficas produzidas pela fonação reversa. Rev CEFAC. 2010;12(4):535-42.

11- Minatogawa GJF, Turcio KHL, Guiotti AM, Brandini DA, Zuim PRJ. Movimentos mandibulares: Influência do tratamento da DTM e fonação, analisada por meio de eletrognatografia. Procedimentos do 4 - Congresso Odontológico de Araçatuba. 201421 a 24 de Maio. Revista de Odontologia da UNESP. 2014;43:150.

12- Oliveira IAM. Prevalência de Disfunção Temporomandibular em Professores do Ensino Médio. [dissertation].Bahia: Universidade Federal da Bahia; 2013.

13- Chaves TC, Oliveira AS. Grossi DB. Principais instrumentos para avaliação da disfunção temporomandibular, parte I: Índices e questionário, uma contribuição para a parte clínica e pesquisa. Fisioter Pesqui. 2008;15(1):92-100.

14- Costa LMR, De Medeiros DL, Ries LGK, Beretta A, De Noronha MA. Avaliação das adaptações transculturais e propriedades de medida de questionários em língua portuguesa relacionados às desordens temporomandibulares: uma revisão sistemática. Fisioterapia e Pesquisa. 2014;21(2):107-12.

15- Sfhinix Brazil, Google analytic [Internet]. Avaliable from: http://www. sphinxbrasil.com/assets/files/tutoriais/Analise_de_uma_tabela_cruzada_ simples.pdf.

16- Beasley CR. Bioestatística usando R: Apostila de exemplos para o Biólogo. Bragança-PA. Apostila escrita para alunos da disciplina de Biometria do curso de Ciências Biológicos do Campus de Bragança - Universidade Federal do Pará. 2004.

17- Figueiredo VMG, Cavalcanti AL, De Farias ABL, Do Nascimento SR. Prevalência de sinais, sintomas e fatores associados em portadores de disfunção temporomandibular-DOI. Acta Scientiarum. Health Sciences. 2009;31:159-63.

18- Tavarez RRDJ, Braga PLA, Maia Filho EM, Malheiros AS. Prevalência e gravidade de disfunção temporomandibular em professores do ensino superior. Rev. Dor. 2013;14(3):187-91.

19- Cavalcanti MDOA, Lima JMDC, Batista AUD, Oliveira LMCD, Lucena LBSD. Evaluation of severity of temporomandibular disorders and prevalence of parafunctional habits in military policemen. RGO. Revista Gaúcha de Odontologia. 2011;59(3):351-6.

20- Machado IM, Bianchini EMG, Silva MAA, Ferreira LP. Voz e disfunção temporomandibular em professores. Rev Cefac. 2009;11(4):630-43.

21- Celic R, Jerolimov V, Zlataric DK. Relationship of slightly limited mandibular movements to temporomandibular disorders. Braz Dent J. 2004;15(2):151-4.

22- Campos JADB, Carrascosa AC, Maroco J. Validity and reliability of the Portuguese version of Mandibular Function Questionnaire. Journal of oral rehabilitation. 2012;39(5):377-83.

23- Ohrbach R, Granger C, List T, Dworkin S. Preliminary development and validation of the Jaw Functional Limitation Scale. Community dentistry and oral epidemiology. 2008;36:228-36. 